\title{
INTERESSES E IDÉIAS EM POLÍTICAS PARTICIPATIVAS: reflexões a partir dos comitês de bacia hidrográfica e os orçamentos participativos
}

Rebecca Abers*

\begin{abstract}
Resumo: Este artigo analisa políticas participativas criadas pelo Estado sob a perspectiva da "autoridade", isto é, a capacidade de novos fóruns decisórios de solucionar problemas, fazer valer decisões e ter impacto no mundo externo. A partir do exemplo de dois tipos de políticas participativas - comitês de bacia hidrográfica e orçamentos participativos -, argumenta-se que a construção da autoridade é mais provável nos casos em que tanto atores de Estado quanto da sociedade percebem que o novo processo decisório pode beneficiar seus interesses. De um lado, o artigo mostra como os atores envolvidos em experiências bem-sucedidas formulam políticas participativas em torno de interesses compartilhados. De outro lado, são examinados os fatores cognitivos que facilitam ou, ao contrário, dificultam a identificação de tais interesses. Mostra-se, ainda, que idéias técnicas, tais como os modelos de participação, podem ajudar os atores a perceber a criação de fóruns participativos como sendo de seu próprio interesse; entretanto, quando esses modelos são seguidos cegamente, eles podem tornar-se "cadeados cognitivos", dificultando assim a capacidade de adaptar idéias às condições locais.
\end{abstract}

Palavras-chave: políticas participativas, comitês de bacia hidrográfica, orçamento participativo, ação coletiva, idéias.

Desde os anos 90, políticas públicas participativas têm se multiplicado, nos mais diversos formatos, no Brasil. Conselhos locais e nacionais nas áreas de saúde, educação, meio ambiente e nas políticas de alocação de recursos orçamentários, são alguns exemplos

* Pesquisadora Associada do Núcleo de Pesquisa em Políticas Públicas, Universidade de Brasília.

Artigo recebido em 15 ago. 2003; aprovado em 21 set. 2003. 
desta tendência. Diferindo bastante, tanto no que tange à influência sobre decisões governamentais, quanto ao perfil de cidadãos ou grupos que a eles têm acesso, a popularidade de tais mecanismos de participação reflete uma confluência de visões oriundas de diversos setores: partidos de esquerda e de centro, o governo federal, organizações não-governamentais, e organismos multilaterais, como o Banco Mundial.

Todos estes grupos parecem presumir que espaços participativos criados pelo Estado são capazes de adquirir "autoridade", ou "a capacidade de solucionar problemas, fazer valer decisões, e ter impacto no mundo externo" (Abers \& Keck, 2003, minha tradução). Mas a idéia de que autoridade possa surgir de fóruns participativos criados pelo Estado há muito tem sido questionada. Por exemplo, em 1949, o estudo de Selznick sobre participação no Tennessee Valley Authority sugeriu que dificilmente governos devolvem poder aos fóruns participativos que criam. Desde então, inúmeros estudos de caso têm mostrado que os governos não são inclinados a entregar poder de decisão.

Este artigo parte da proposta de que a construção de autoridade em fóruns participativos criados pelo estado é mais provável em casos em que tanto atores de Estado quanto da sociedade percebem que o novo processo decisório pode beneficiar seus interesses. Em outras palavras, poder só é compartilhado quando todos os atores chamados à mesa estão motivados a compartilhá-lo.

A existência de interesses compartilhados é associada ao que Peter Evans chama de "sinergia Estado-sociedade", ou seja, as "relações entre governos e grupos de cidadãos engajados que se reforçam mutuamente" (Evans, 1996, p. 1119, minha tradução). Evans nota que muitas das políticas públicas bem-sucedidas em países menos desenvolvidos revelam a construção de laços entre atores dos dois lados da fronteira entre público e privado. $\mathrm{O}$ autor identifica diversos fatores que explicam ou facilitam a existência destas relações sinérgicas. Embora reconheça o papel de fatores contextuais instituições estáveis e democráticas, existência de capital social, etc. - ele sugere que a maneira como as políticas públicas são formuladas pode ser tão ou mais importante do que o contexto no qual são 
implementadas, às vezes produzindo sinergia onde instituições políticas ou capital social são pouco desenvolvidos.

Este artigo procura melhor compreender como o desenho de políticas participativas está relacionado ao seu nível de autoridade. Argumento que formular políticas de forma a atender os interesses, tanto dos atores estatais encarregados da criação de políticas participativas, quanto dos atores na sociedade chamados a participar, é a chave para que um espaço decisório com autoridade possa emergir. Evans (1996, p. 1127), nota que a existência de "interesses homogêneos" ou "compartilhados" promove a construção de sinergia, mas não analisa o processo de formular políticas que atendem a interesses de atores estatais e da sociedade ao mesmo tempo. Pela análise de dois casos de fóruns participativos - orçamentos participativos e comitês de bacia hidrográfica - este artigo examina como se dá o processo de identificação de interesses compartilhados e o desenho de políticas participativas em torno deles.

Embora este trabalho destaque o papel de interesses na construção de sinergia e autoridade, não se trata de uma análise das "escolhas racionais" dos diversos atores. Pelo contrário, enfatizo como fatores cognitivos influenciam a capacidade dos atores responsáveis pelo desenho de políticas participativas de perceber a existência de interesses compartilhados e imaginar políticas que possam beneficiar mutuamente atores estatais e da sociedade.

$\mathrm{Na}$ próxima seção, discuto teoricamente a relação entre a identificação de interesses compartilhados e idéias técnicas. Em seguida, aplico tais conceitos a exemplos empíricos. Finalmente, apresento algumas conclusões sobre como políticas participativas podem atender a interesses compartilhados e como este processo é influenciado pela forma como os atores envolvidos lidam com idéias técnicas.

\section{Interesses e idéias}

As teorias de ação coletiva já discutiram de forma detalhada porque alguns indivíduos participam de movimentos sociais, de 
associações e na política, enquanto outros não o fazem. Mancur Olson (1965), autor seminal nesse debate, argumentou que os indivíduos tendem a considerar que não vale a pena participar de ação coletiva, a menos que recebam recompensa direta. Desde Olson, inúmeros estudos demonstraram que algumas pessoas participam de ação coletiva mesmo na ausência de tais recompensas. A literatura pósOlson mostra que as pessoas são motivadas por mais do que uma concepção estreita de interesse (Mainsbridge, 1990). Ainda assim, existe suficiente evidência de que elas aderem a processos de ação coletiva quando acreditam que, ao fazê-lo, irão receber alguma espécie de retorno, seja para elas próprias, seja para a causa que defendem. A teoria dos movimento sociais se referiu a "estruturas de oportunidade política”. A existência de problemas não é o bastante para mobilizar atores. Eles têm que chegar à conclusão de que existem oportunidades reais para resolvê-los (Tarrow, 1994; Tilly, 1978; Mellucci, 1989).

Esta abordagem sugere que não se pode esperar que a simples abertura de novos fóruns decisórios pelo Estado motive a participação de atores da sociedade, que precisam perceber que as decisões tomadas em tais fóruns darão retorno positivo para os interesses ou causas que identificam como importantes. Os cidadãos participantes precisam entender as decisões a serem tomadas como relevantes. Também precisam acreditar que elas serão respeitadas, ou seja, que o processo tem credibilidade (Abers, 2000, p. 136-39).

Para explicar processos participativos é preciso não apenas entender as motivações de cidadãos participantes, mas por que os atores estatais criam e apóiam tais fóruns. Não é óbvio por que os detentores de poder de decisão no Estado escolheriam reduzir o seu próprio controle sobre decisões por meio da devolução de poder a grupos fora do Estado, especialmente quando tais grupos são excluídos das decisões precisamente por disporem de pouco poder econômico ou político. No entanto, atores estatais podem se interessar em promover a participação por uma série de razões: por acreditarem que participação leva a projetos mais bem-sucedidos; por pressão de organizações cívicas; por pretenderem dar maior legitimidade às decisões; ou por influência de doadores, em especial agências de 
desenvolvimento. Quando não existe tal vontade política, é extremamente improvável que governos criem oportunidades para que grupos cívicos influenciem o processo de tomada de decisões (Abers, 2000, p. 2001).

Essa visão pressupõe que atores do Estado se comportem de forma bastante similar aos atores da sociedade: ambos tentam alcançar objetivos usando os instrumentos disponíveis e em circunstâncias restritivas. Mas no caso dos atores de Estado, os instrumentos são o uso do aparato estatal e as restrições são os limites ao uso de tal aparato para os fins que individualmente almejem. Tais restrições e limites podem ser de ordem financeira, política, legal, ou prática. Da mesma forma que atores da sociedade agem em resposta a "estruturas de oportunidades", atores estatais decidem usar o aparato estatal de certa maneira em resposta a mudanças no clima político e institucional, o que inclui mudanças nas demandas por parte da sociedade.

Como na sociedade os interesses de atores estatais são variados, atores "políticos", que dependem diretamente da continuidade de apoio político (partidário, eleitoral, ou de outro tipo), tendem a se orientar por objetivos diferentes daqueles que influenciam atores estatais "técnicos". Não convém aqui analisar quais são os interesses ou os objetivos desses atores. O importante é ressaltar que processos participativos precisam animar os interesses de todos os envolvidos para que sejam bem-sucedidos. Fóruns participativos dotados de autoridade raramente acontecem porque é raro que existam interesses compartilhados. Normalmente, os interesses dos vários atores são diferentes demais.

No entanto, nem mesmo a existência de interesses compartilhados é suficiente. A ação coletiva pode não ocorrer mesmo quando a construção de um processo participativo seria de benefício mútuo para atores de Estado e sociedade. Para compreender esse problema, é preciso recorrer a uma análise menos racionalista do que a usada até agora: a construção da sinergia não depende apenas de uma confluência de interesses, mas da capacidade de os atores perceberem que tal confluência existe. Mellucci (1989, p. 34) lembra- 
nos que a ação coletiva não depende apenas de oportunidades, mas da capacidade de os atores reconhecerem que elas existem. De forma semelhante, na área de políticas públicas, vários autores abordam a importância de idéias técnicas para a compreensão das motivações. Idéias técnicas ajudam os indivíduos a definir seus interesses e sugerem alternativas para persegui-los (Blyth, 2001; March \& Olsen, 1989; Sabatier, 1995; Weir, 1994). No seu estudo sobre política econômica na Suécia, Blyth (2001) mostra como idéias técnicas podem ter implicações tanto positivas quanto negativas no que tange à capacidade de as políticas públicas resolverem problemas. Por um lado, o autor nota idéias que servem como "projetos institucionais" (institutional blueprints) (Blyth, 2001, p. 3), ensinam os atores como interpretar problemas e quais instrumentos podem ser utilizados para resolvê-los. A circulação de novas idéias entre profissionais pode abrir perspectivas, redefinir problemas e sugerir novas soluções.

Idéias sobre políticas participativas têm tido essa função, na medida em que possibilitam novas interpretações para os problemas. Em função de tais idéias, é cada vez mais aceito que políticas malsucedidas são principalmente resultado da falta de consenso político. Ao mesmo tempo, essas idéias propõem uma nova solução: a criação de mecanismos participativos. Idéias sobre políticas participativas são compartilhadas por tantos setores (desde partidos de esquerda ao Banco Mundial) que as propostas de criação de fóruns participativos têm hoje muito mais chance de ganhar apoio do que no passado. ${ }^{1}$

Por outro lado, Blyth (2001, p. 4) nos avisa: idéias técnicas podem também servir como "cadeados cognitivos" (cognitive locks). Ele argumenta que, freqüentemente, atores são incapazes de agir em favor dos seus interesses objetivos porque as idéias predominantes na sua área de atuação dificultam a invenção de novas soluções. Adaptando essa proposição à nossa discussão, atores podem não conseguir perceber as oportunidades para definir políticas participativas que atenderiam a interesses compartilhados porque estão tão acostumados com velhas formas de agir, ou tão influenciados por modelos técnicos, que não conseguem imaginar outras alternativas. 
Argumento neste trabalho que não são apenas idéias técnicas não-participativas que podem bloquear a criação pelo Estado de espaços participativos com autoridade. Modelos de políticas participativas também podem ter este impacto. Da mesma forma que idéias sobre participação podem encorajar os formuladores de políticas públicas a abrir espaços decisórios à influência de atores da sociedade, modelos muito fechados podem constranger tanto quanto facilitar a emergência de autoridade. Quando os que formulam as políticas participativas "seguem" modelos, sem considerar a constelação de interesses que existe num contexto específico, é menos provável que as políticas concebidas atendam a interesses compartilhados e, portanto, ganhem autoridade. Modelos muito específicos, como os de comitês de bacia e de orçamentos participativos, correm o risco de se tornarem "cadeados cognitivos" à medida que os formuladores de políticas se limitam a "seguir o modelo" ou "imitar os bem-sucedidos" em vez de adaptar tais modelos às suas circunstâncias. ${ }^{2}$

\section{Dois tipos de políticas}

No intuito de verificar se a abordagem apresentada acima contribui para explicar a existência de autoridade nos fóruns participativos, discutirei dois exemplos de políticas participativas substancialmente diferentes: o orçamento participativo e os comitês de bacia hidrográfica. Ambas as políticas tomam vulto no Brasil, o que propicia um grande número de casos de onde extrair informações. Em 2000, 140 municípios brasileiros desenvolviam modelos de orçamento participativo (Ribeiro \& Grazia, 2003, p. 13). De forma análoga, existem hoje cerca de 100 comitês de bacia hidrográfica implantados. Os argumentos relativos ao Orçamento Participativo, no entanto, baseiam-se principalmente no estudo de um único caso (Porto Alegre), embora de grande importância histórica, ao passo que a reflexão sobre gestão de bacias fundamenta-se na análise comparativa de 18 estudos de caso, conduzidos por mim e por colegas no âmbito de um projeto de pesquisa colaborativo, o Projeto Marca D’Água. ${ }^{3}$ 


\section{Comitês de bacia}

Embora existam algumas experiências anteriores de comitês de bacia hidrográfica, um modelo participativo, com a inclusão de representantes da sociedade civil e do setor privado, começou a ser implementado no Brasil apenas a partir dos anos 90. A pesquisa sobre esse tema ainda está em curso, o que torna o caráter de minhas reflexões inicial.

Historicamente, a política de recursos hídricos tem sido tecnocrática e centralizada nos níveis federal e estadual de governo, virtualmente sem a participação da sociedade civil ou de instituições municipais. As decisões sobre o assunto eram, em geral, tomadas por órgãos públicos ligados ao setor de geração de energia, em função da importância da gestão dos rios para o setor. Por outro lado, as decisões relativas à irrigação eram tomadas pelos órgãos governamentais ligados à agricultura e as decisões relativas ao saneamento pelas companhias estaduais do setor ou, em alguns casos, pelas companhias municipais. A cultura tecnocrática dominava o setor, o que possibilitava quase nenhuma participação de usuários, da sociedade civil ou de governos municipais.

Nos anos 90, alguns Estados aprovaram legislação para mudar esse cenário. São Paulo foi o primeiro, em 1991, seguido pelo Ceará, em 1992, e depois por outros. Em 1997, a Lei n ${ }^{\circ} 9.344 / 97$ instituiu a nova política nacional de recursos hídricos. Desde então, a maioria dos Estados fora da região amazônica aprovaram leis de gestão da água. As novas leis procuram integrar o processo de tomada de decisão entre os diferentes órgãos públicos, descentralizando-o ao nível de bacia hidrográfica e incorporando a participação do setor privado e da sociedade civil. Um ponto central é a proposta de criação, em cada bacia hidrográfica, de comitês envolvendo órgãos estaduais e locais, usuários de água e organizações civis. Esses comitês, que em alguns Estados tinham a maioria de segmentos não estatais, deveriam tomar as decisões mais importantes para a gestão integrada dos recursos hídricos da bacia como um todo. Outro aspecto central do novo modelo de gestão é a cobrança pelo uso da água. Conforme a maioria das leis, os comitês de bacia decidiriam tanto os critérios de 
cobrança quanto a alocação dos recursos arrecadados. No entanto, exceto no caso da Bacia do Paraíba do Sul, a cobrança ainda não foi implementada da forma prevista. ${ }^{4}$

Nesse contexto, não surpreende que, na maioria dos casos estudados pelo Projeto Marca d'Água, a autoridade dos comitês seja ainda muito frágil e freqüentemente inexistente. No entanto, alguns comitês vêm adquirindo influência nas ações tanto do setor público quanto do setor privado.

\section{1) Interesses}

A comparação de experiências de comitês de bacia sugere a existência de dois caminhos pelos quais os comitês adquirem algum nível de autoridade. Em cada caminho, é possível verificar que a sinergia entre as motivações dos vários tipos de atores envolvidos é essencial para a construção dessa autoridade.

\section{Respostas a oportunidades criadas de cima para baixo}

A criação de comitês de bacia não pode ser analisada separadamente do processo maior de mudança da legislação e da criação de novas instituições para a gestão integrada nos níveis estadual e federal. Em vários Estados, a criação de comitês começou a partir da ação de órgãos governamentais que organizaram processos de mobilização em determinadas bacias. Em alguns casos, tais ações não poderiam ser caracterizados exatamente como "de cima para baixo", já que os atores dentro dos governos atuavam em articulação próxima com atores da sociedade e das bacias. Em São Paulo, por exemplo, a criação de uma política estadual de recursos hídricos, que daria grande ênfase na criação de comitês em todo o Estado, foi promovida por uma rede de pessoas, que trabalhavam tanto em órgãos estaduais quanto em bacias específicas. Os primeiros comitês foram criados com grande participação desses mesmos atores (Keck, 2002a). No entanto, em São Paulo como em alguns outros estados, muitos comitês foram posteriormente criados sem tal sinergia.

No início, a maior parte dos comitês criados por órgãos governamentais era não mais que mera formalidade. Por exemplo, na 
bacia do Rio das Velhas, em Minas Gerais, um comitê foi criado às pressas e com pouca participação da sociedade civil, pois não havia entidades na bacia organizadas em torno da questão da água. Essa ausência se refletiu no funcionamento do Comitê Velhas, que durante mais de um ano não conseguia nem quorum para votar seu próprio regimento interno (Abers, 2002).

Comitês são, assim, criados "de cima para baixo" por várias razões. Em alguns casos, como em São Paulo, são produto da interação entre redes de técnicos estaduais e atores na sociedade civil, que conseguem promover uma nova política estadual. Às vezes, o governo federal presta apoio ativo para a criação e consolidação de comitês de bacia. A Agência Nacional de Águas (ANA), por exemplo, desde sua criação em 2001, tem se envolvido diretamente na criação de comitês federais de bacia e na promoção de mecanismos de cobrança pelo uso de água em uma das bacias federais, a do Rio Paraíba do Sul. Algumas políticas da ANA também vinculam financiamento à criação de comitês.

Em outros casos, existem fortes influências de agências financiadoras. No caso do Comitê Velhas, a criação, de cima para baixo, do comitê resultou da necessidade de cumprir uma exigência do Banco Mundial, como parte de um grande empréstimo para obras de saneamento na região metropolitana de Belo Horizonte. Preocupações com a boa administração dos recursos, transparência, combate à corrupção e garantia de visibilidade política provavelmente explicam o fato de que, nos anos 90, vários projetos de saneamento financiados pelo Banco Mundial e o Banco Interamericano de Desenvolvimento (BID) tinham componentes relacionados à gestão de águas. Normalmente, focalizavam o fortalecimento da capacidade do Estado na gestão de recursos hídricos. Mas, em alguns casos, incluíam exigências específicas por mecanismos participativos de decisão. Por exemplo, no Ceará, o Banco Mundial incluiu como condição de contrato que o Estado promovesse uma reforma na gestão de recursos hídricos, incluindo a criação de mecanismos participativos (Garjulli et al. 2002; Kemper \& Olson, 2001).

Em São Paulo, comitês também se mobilizaram em torno de oportunidades para financiamento, mas de forma diferente. Naquele 
Estado, enquanto se lutava sem sucesso pela aprovação de leis possibilitando a implementação da cobrança pelo uso da água, uma lei criando o FEHIDRO, um fundo destinado ao financiamento de obras de saneamento e outros projetos ligados à gestão de águas, foi da maior importância. Uma vez que a lei dava aos comitês o controle sobre a alocação dos recursos do FEHIDRO, os governos municipais e organizações da sociedade civil passaram a ter forte incentivo para aderir aos comitês. Depois que esse fundo foi criado, mais de 20 comitês foram criados em São Paulo, a maioria deles empenhados na discussão de como alocar os recursos do FEHIDRO (Branco, 2000).

Existem evidências de que os comitês que se mobilizam inicialmente para cumprir um programa governamental, ou para obter recursos, podem mais tarde ganhar escala e adquirir uma autoridade mais ampla. Na medida em que as pessoas envolvidas percebem que os comitês podem ser um espaço efetivo para a tomada de decisões, elas começam a abordar questões maiores. Por exemplo, no caso do Comitê Velhas, inicialmente criado apenas para cumprir uma exigência de contrato, o "casco vazio" do comitê foi aos poucos "recheado" por atores, tanto do governo quanto da sociedade, que enxergaram uma oportunidade de influenciar as políticas de água. Hoje, cinco anos depois da sua criação, não só participam ativamente no comitê lideranças da sociedade civil, usuários e governos municipais, como suas decisões são respeitadas pelo poder público.

Em outros casos, a possibilidade de acesso a recursos financeiros serviu de "gatilho" para construir sinergias e ampliar o raio de influência dos comitês. Por exemplo, no Comitê do Litoral Norte, em São Paulo, os atores originalmente se mobilizaram com o objetivo de ter acesso aos recursos do FEHIDRO. Durante os primeiros anos, o principal tema de discussão foi a alocação pontual desses recursos. Aos poucos, no entanto, o comitê foi ampliando suas preocupações. Eventualmente, desenvolveu-se um plano para o uso de recursos hídricos na bacia (Keck, 2002) e a tentativa de integrar o planejamento de água com outros processos de planejamento (por exemplo, municipal) na bacia. ${ }^{5}$ Essas mudanças parecem ter sido resultado das experiências iniciais em torno da distribuição de recursos financeiros, 
quando os atores aprenderam a trabalhar juntos e começaram a perceber seus interesses comuns. Ou seja, a partir de ações mais imediatistas e localizadas, os atores reconhecerem a existência de uma oportunidade para atender a interesses compartilhados em níveis mais amplos.

\section{Alianças em torno de problemas concretos}

Embora muitos dos comitês de bacia tenham sido criados como resultado dos fatos mencionados acima, os que se mostraram mais capazes de ganhar algum nível de autoridade foram aqueles que, criados com base em alianças entre atores de Estado e atores de sociedade, visavam a resolução de problemas concretos. Embora esse seja o caso de vários dos comitês mais bem-sucedidos, dois exemplos ilustram a tese.

Na Bacia do Rio Itajaí, em Santa Catarina, região sujeita a inundações periódicas, associações de classe, autoridades municipais e pesquisadores da universidade criaram um comitê. O grupo havia se organizado informalmente em 1996, para propor intervenções na gestão da bacia que poderiam reduzir os prejuízos causados pelas inundações. Antes do seu reconhecimento e instalação formal pelo governo do Estado, esse grupo já buscava influenciar a gestão da água, começando com uma grande oficina reunindo atores diversos de toda a bacia. A efetividade da rede de atores revelou-se no fato de que várias propostas da oficina acabaram sendo incorporadas em parcerias entre empresas, e em convênios com os governos federal e estadual (Frank \& Bohn, 2000; Mais, 2002). Alguns anos depois, foi possível identificar o comitê como um espaço decisório que tinha autoridade. Especialmente, o comitê foi capaz de influenciar um grande projeto de controle de inundações financiado por uma agência de cooperação do Japão e que se encontrava paralisado por causa das difíceis negociações entre tal instituição e o governo de Estado. As sugestões oferecidas pelo grupo, e que resultaram em profundas alterações no projeto original, foram acolhidas porque ambos, governo estadual e organismo internacional, acreditavam que, ao ouvir o comitê, estariam dando maior legitimidade ao projeto. $\mathrm{O}$ comitê continua trabalhando efetivamente desde então. $\mathrm{O}$ sucesso derivou 
do reconhecimento de que o grupo criou um espaço legítimo para a negociação entre atores relevantes. Ou seja, a sinergia existente no comitê - que resultou na mobilização de diversos atores em torno da resolução de problemas concretos que prejudicavam a todos - produziu uma legitimidade que se tornou fonte de autoridade.

Um segundo exemplo é o caso do Ceará. Em 1994, um grupo de técnicos da Companhia de Gestão de Recursos Hídricos (COGERH) começou a organizar comissões de usuários em nível de bacia para enfrentar problemas crônicos de escassez e uso predatório de água. As comissões de usuários reuniram-se anualmente para aprovar planos para o uso de água de centenas de reservatórios, de forma a otimizar o consumo de água para o máximo de usuários. Ao prover oportunidade aos usuários para negociar e estabelecer limites ao uso, as comissões reduziram o desperdício e aumentaram a oferta de água. Com os compromissos implícitos nos planos de utilização, a tendência a estocar água com fins preventivos se reduziu dramaticamente (Garjulli et al., 2002).

Segundo Lemos \& Oliveira (2003), o sucesso da experiência cearense, que instituiu um processo participativo e transparente de decisão num setor historicamente dominado por políticas clientelísticas, é devido precisamente à construção de laços entre atores estatais e da sociedade, ou seja, à sinergia. Tais laços provavelmente foram mais fáceis de construir no Ceará por causa da natureza do problema. A falta de água afetava múltiplos atores na sociedade e era de interesse do Estado resolver o problema, já que historicamente esse era um dos principais temas políticos na região. Existia ainda um grupo de técnicos do órgão estadual de gestão de água que seguiam um projeto ideológico de democratização e mobilização da sociedade, algo incomum na área de recursos hídricos. Ou seja, diferentes interesses e causas convergiram em torno da mesma solução. A facilidade de identificar um problema concreto e reconhecer que resolvê-lo traria benefícios a todos, certamente, facilitou a construção de sinergia.

Mas, como notado anteriormente, a existência de interesses compartilhados não é suficiente. O problema da falta de água no Ceará 
e do seu excesso no Vale do Itajaí são históricos. Mas não levaram antes à colaborações entre Estado e sociedade. Temos, portanto, que perguntar por que a ação sinérgica é possível em alguns casos e alguns momentos, mas não em outros.

\section{2) O papel das idéias}

Exemplos como os apresentados acima são, na verdade, raros entre os comitês de bacia. Criados, em sua grande maioria, para atender exigências legais ou financeiras, poucos encontraram um objetivo concreto em torno do qual a sinergia entre as motivações dos vários atores pudesse ocorrer. Em alguns casos, é possível que simplesmente não exista um problema potencial em torno do qual atores em diversas esferas possam se articular. No entanto, a análise dos casos em que se criou sinergia nos comitês de bacia sugere outro provável obstáculo: a prevalência de um cadeado cognitivo que dificulta a "descoberta" de que os comitês podem ser espaços de resolução de problemas específicos.

Existe no campo técnico de recursos hídricos um modelo ideal de gestão bem definido. Esse modelo é, em grande parte, baseado na experiência francesa de gestão de recursos hídricos. Nas últimas duas décadas, experiências como a da França têm sido reconhecidas no meio técnico internacional e codificadas em "princípios" aprovados em reuniões internacionais, especialmente na Conferência Internacional de Água e Meio Ambiente, que ocorreu em Dublin, no ano de 1991. As idéias estão muito disseminadas no meio técnico brasileiro, em parte pela influência de projetos de cooperação técnica com o governo francês, mas também pelo grande trânsito de técnicos brasileiros no meio internacional (Formiga Johnsson, 1998). Na sua maioria, as diversas políticas estaduais e a política nacional de recursos hídricos também expressam essas idéias técnicas, embora com algumas modificações.

Como um reflexo da ideologia técnica, as leis já definem sobre $o$ quê os comitês devem deliberar. São enumerados vários "instrumentos de gestão" sobre os quais os comitês têm poder decisório (esse poder varia substancialmente de Estado para Estado). Esses 
instrumentos são relativamente abstratos, trabalhando sempre em nível de bacia. Incluem, por exemplo, a formulação de planos de uso de recursos hídricos, a definição do "enquadramento" de rios (uma definição de metas de qualidade da água em cada trecho do rio), a concessão de outorga pelo uso da água, e o mais importante, a cobrança pelo uso da água. Os comitês deveriam ter poderes normativos, podendo definir critérios para outorga, procedimentos e valores da cobrança, além de planejar o uso dos recursos da cobrança no âmbito da bacia.

A ampla aceitação desse modelo no meio técnico, fortalecida por legislação, certamente aumenta as chances de que os formuladores de políticas de água criem mecanismos participativos de gestão, além de explicar em parte a rápida disseminação de comitês de bacia pelo Brasil afora. Mas, nem sempre as idéias participativas promovem a busca de soluções adaptadas aos interesses locais. Pelo contrário, em grande parte dos casos, os formuladores de políticas de recursos hídricos parecem estar criando comitês "por obrigação". Esses comitês se reúnem pouco e discutem principalmente temas associados à sua própria organização interna, em detrimento de problemas substanciais ou suas soluções. ${ }^{6}$

O grande impedimento à implementação desse modelo de participação é que, embora as leis tenham sido aprovadas e muitos comitês tenham sido criados, a cobrança pelo uso da água requer, na maioria dos casos, legislação complementar e avanços institucionais (como cadastros completos de usuários) que ainda não existem. ${ }^{7}$ Já que o seu papel central na cobrança seria, pelo modelo (e pelas leis), a principal fonte de autoridade dos comitês, não surpreende que muitos comitês têm pouca capacidade de mobilização. Os membros parecem aguardar que o modelo passe a fazer sentido, ou seja, que a cobrança seja implementada, para começarem a atuar. Podemos dizer que esses atores não têm atuado porque o modelo não é relevante para a realidade em que vivem.

Os casos de exceção, como os descritos no item anterior, têm uma característica comum: as principais ações dos comitês não tratam 
dos "instrumentos de gestão". Em detrimento de deliberações normativas sobre critérios de outorga, enquadramento do rio, planos de usos, etc., esses comitês se formaram em torno da definição de soluções para problemas concretos e específicos. Esse tipo de ação não faz parte do modelo e também não está definido na legislação como competência dos comitês. Assim, a autoridade desses comitês não decorre nem do modelo nem das leis, mas de um poder informal adquirido ao se conseguir juntar atores chaves, negociar novas soluções e resolver problemas.

Podemos dizer que as idéias técnicas tiveram uma dupla função, encorajando inovações e, em outros casos, constrangendo inovações. Por um lado a popularidade de mecanismos participativos no meio dos recursos hídricos ajudou os atores a conceber e depois a legitimar ações colaborativas. ${ }^{8}$ Por outro lado, para que os mecanismos participativos realmente ganhassem autoridade, era necessário fugir do modelo, ora criando comitês em torno de outros propósitos que não os "instrumentos de gestão", como no caso do Itajaí, ora criando outros tipos de espaços decisórios que não os comitês, como é o caso do Ceará. Em cada um desses casos, os atores foram criativos: em vez de seguir o modelo, foram capazes de adaptá-lo à constelação local de interesses.

\section{Orçamento participativo}

Para aprofundar a discussão sobre a relação entre interesses e idéias, discuto agora uma política participativa bastante diferente, o Orçamento Participativo (OP), que ganhou destaque no Brasil em função do sucesso do Partido dos Trabalhadores (PT) no governo de Porto Alegre, iniciado em 1989. Desde então, essa política tornou-se não apenas o carro-chefe dos governos municipais do PT em todo o país, como tem sido adotada por governos municipais e estaduais de outros partidos (Ribeiro \& Grazia, 2003, p. 38). Implementada em uma variedade de formas, o OP geralmente envolve a divisão do município em "regiões de orçamento" e a criação de fóruns nos quais delegados eleitos em assembléias regionais abertas decidem como os 
investimentos de capital devem ser distribuídos dentro de cada região. Algumas cidades instituíram também "fóruns temáticos", que decidem gastos para a cidade inteira em áreas como educação, infraestrutura de transporte, etc. Em algumas cidades, apenas parte dos investimentos de capital estão disponíveis para a decisão participativa. Em outras, se decide sobre a alocação de todo o orçamento. Nos locais em que a política funciona melhor, as decisões aprovadas pelos fóruns participativos são plenamente incorporadas à proposta orçamentária do Executivo, raramente emendadas pelo Legislativo, e então implementadas pelo Executivo.

Em Porto Alegre, o OP encontra-se em seu décimo quinto ano consecutivo. Fóruns participativos foram criados em todos os níveis mencionados acima. Existem dezesseis fóruns regionais e seis fóruns temáticos. O Conselho Municipal de Orçamento inclui tanto representantes dos fóruns regionais quanto dos fóruns temáticos e tem a responsabilidade de analisar todo o orçamento. O Conselho aprova as categorias orçamentárias gerais; examina, de forma seletiva, aspectos específicos do orçamento; examina e aprova a dotação de recursos para despesas de capital entre os órgãos municipais; examina e aprova projetos de infra-estrutura de maior porte; e define os critérios que regem a divisão de investimentos entre as diversas regiões do município. Alocam-se dotações específicas para cada região, por tipo de investimento (infra-estrutura sanitária, pavimentação, saúde, etc.). As prioridades estabelecidas por fórum regional são integralmente respeitadas até o limite da dotação.

Desde que a política se iniciou, entre dez e quinze mil pessoas participam nas assembléias de orçamento a cada ano. Estudos mostram que os pobres dominam os fóruns de orçamento e que a vasta maioria dos participantes acredita que o governo, de fato, respeita as decisões tomadas (Abers, 2000; Fedozzi, Pozzobon \& Abers, 1995). Pesquisa realizada em duas das regiões mostrou que, embora o governo tenha, algumas vezes, deixado de implementar certos projetos no ano fiscal, quase todos os projetos aprovados pelos fóruns foram eventualmente implementados ou renegociados (Abers, 2000). 
O OP de Porto Alegre representa uma significativa transferência de poder dos setores tradicionais e das elites empresariais para os pobres, que dominam as assembléias. Estudos recentes têm mostrado uma mudança significativa no padrão de alocação dos recursos públicos: as regiões mais pobres foram beneficiadas de forma nítida e substancial (Marquetti 2001). A criação de mecanismos de tomada de decisão transparentes também levou a um declínio na corrupção e na ineficiência administrativa. Pesquisas de opinião mostram que a população vê o governo não apenas como democrático e aberto à participação mas, também, como eficiente, moderno e dinâmico (Abers, 2000). ${ }^{9}$

\section{1) Interesses}

\section{Estratégia política}

Minha análise sobre as razões da consolidação do OP em Porto Alegre, desenvolvida em detalhes em outros trabalhos (especialmente Abers, 2000, 2001), relaciona diretamente a decisão de devolver poder aos pobres a uma estratégia política bem-sucedida. Embora não exatamente o resultado de uma estratégia intencional ao longo da primeira administração petista (1989-1992), o OP tornou-se a peça central do PT para a reeleição. Ao invés de tentar competir nas arenas tradicionais, onde políticas clientelistas servem para angariar apoio político, a administração de Porto Alegre construiu, com sucesso, uma coalizão política alternativa em torno do Orçamento Participativo.

Pelo menos três grupos sociais em Porto Alegre apoiaram essa política participativa específica. Ao privilegiar inicialmente investimentos em infra-estrutura comunitária, o OP respondeu a demandas de lideranças de bairro que, tradicionalmente, dependiam de mecanismos de troca de favores clientelísticos. Uma vez que grande parte dessas lideranças era ligada ao principal partido de oposição (PDT), a administração ganhou poder de barganha para negociar com a Câmara Municipal e aprovar projetos de lei cruciais para o aumento 
de arrecadação fiscal. Isso, por sua vez, tornou possível à administração responder às demandas dos participantes. Setor chave da elite econômica local, as empreiteiras apoiaram de forma velada a administração (pressionando também a Câmara Municipal a aumentar o Imposto Predial e Territorial Urbano) porque se beneficiaram do aumento sem precedentes nos investimento em infra-estrutura. Finalmente, e talvez mais importante: a política ganhou o apoio da classe média, que desejava um governo associado à justiça social, transparente e decidido a combater a corrupção. É importante ressaltar que o OP teve início justamente quando grandes escândalos de corrupção no governo federal levaram a manifestações de rua por todo o país. O otimismo quanto à possibilidade de se eliminar a corrupção naquele momento histórico certamente beneficiou o governo de Porto Alegre. A atenção nacional e internacional que a política de OP atraiu ao longo do segundo governo do PT aumentou ainda mais a popularidade da política na classe média.

O OP também contribuiu de forma indireta para que o PT ganhasse apoio político, à medida que, ao gerar forte efeito de coordenação das ações de governo, contribuiu para que se gerasse uma imagem de competência administrativa. ${ }^{10}$ A partir do momento em que as decisões orçamentárias tiveram que passar pelo Conselho Municipal de Orçamento, a administração teve que gerar mecanismos para organizar as informações e controlar os gastos de órgãos municipais que anteriormente tinham grande autonomia. $\mathrm{O}$ resultado foi que o processo participativo contribuiu para aumentar a governabilidade e a efetividade da administração. ${ }^{11}$

Uma das razões para essa melhora no nível de eficiência administrativa foi o fato de que a política era viável na prática, estando concentrada, inicialmente, em pequenas obras que não requeriam financiamento externo ou capacidade técnica extraordinária. Só depois que a política de OP ganhou inércia, fundada em obras simples e de pequena escala, é que grandes obras de infra-estrutura e outros componentes do orçamento passaram a ser decididos com base em amplo debate participativo. 


\section{Interesses na sociedade}

Uma das características notáveis do OP é sua capacidade de motivar a participação das parcelas mais pobres da sociedade. Estudos mostraram que a renda média dos participantes é significativamente menor do que da população em geral (Fedozzi, Pozzobon \& Abers, 1995; Cidade, 1999). Além disso, poucos anos depois que a política se iniciou, a maioria dos bairros que participavam eram aqueles que, antes de 1989, tinham pouca ou nenhuma experiência de mobilização cívica. A mobilização dos pobres e dos até então fracamente organizados ocorreu por uma série de razões. Primeiro, como a participação inicial visava à obtenção de infra-estrutura comunitária básica, o processo começou respondendo diretamente às demandas de associações das regiões. As demandas por obras de infra-estrutura já há muito motivavam manifestações e protestos em diversas regiões da cidade, gerando fortes associações de base popular em sua defesa. As questões discutidas e decididas pelo OP eram, portanto, importantes e de fácil compreensão para os habitantes das regiões pobres.

Se, por um lado, a política atraiu os pobres, por outro foi capaz de se contrapor à tendência de que os fóruns fossem dominados pelos grupos mais capazes de se organizar. No início, a maioria dos participantes nos fóruns de orçamento eram associações das regiões pobres que melhor haviam se organizado na década anterior à chegada do PT ao poder. Mas quando as notícias de que a prefeitura estava investindo em projetos priorizados pelas assembléias de bairro, inúmeros grupos de diversos bairros se formaram e aderiram ao processo. Uma vez mais, o foco temático do OP incentivou essa participação. A maioria dos investimentos realizados - tais como pavimentação de ruas e construção de novas escolas - era altamente visível. Muitos dos participantes que entrevistei declararam ter se juntado às assembléias de orçamento só depois de, vendo tais obras executadas em áreas adjacentes, terem procurado as autoridades ou associações comunitárias para saberem como conseguir tais benefícios em seus bairros. Quando ouviam que os grupos que haviam participado das assembléias de orçamento tinham a chance de receber tais investimentos, eles começavam a organizar seus próprios bairros. 
Muitos moradores de bairros pobres, cuja desconfiança em relação a promessas de políticos lhes tornara céticos quanto a desperdiçar seu precioso tempo com participação, por causa desse "efeito demonstração", passaram a crer que a política merecia credibilidade e que a ação cívica poderia valer a pena.

\section{Dando escala à participação}

Depois de alguns anos trabalhando somente com obras comunitárias, a política de orçamento passou a incluir uma série de "Fóruns Temáticos" em áreas como educação, saúde e transporte. Além disso, ao longo dos anos, a cidade criou outros conselhos para lidar com questões mais gerais, ao invés de apenas questões de orçamento, tais como política de habitação e planejamento urbano. Essa expansão enfrentou novas dificuldades. Por um lado, foi mais difícil mobilizar o governo para apoiá-los, uma vez que os órgãos públicos resistiam a um aumento do controle participativo sobre suas ações. Por outro lado, a natureza mais ampla e menos imediata dessas questões fazia com que parecessem menos relevantes para os moradores dos bairros.

Mesmo assim, minha pesquisa mostrou que a experiência com o primeiro estágio do OP ajudou a garantir que processos participativos fossem bem-sucedidos mesmo quando as questões ganhavam escala. Isso ocorria porque a experiência em escala menor ajudava a emprestar credibilidade à tese de que processos de tomada de decisão participativos funcionam tanto para os atores do Estado quanto para os participantes. À medida que a participação se mostrava bemsucedida em menor escala, ficava mais fácil para o governo pressionar os órgãos municipais a expandir os processos de tomada de decisão participativos. Atores de Estado técnicos também ganharam experiência com métodos participativos e passaram a respeitar a tese de que o planejamento participativo pode ser eficiente. Da mesma forma, moradores de bairros pobres aprenderam como o governo funciona e passaram a entender melhor as causas de muitos dos problemas que enfrentavam. Embora muitos tenham deixado de participar assim que ganharam as obras que lhes motivaram a participar, alguns acabaram por expandir seu potencial de ativismo em outras áreas. 


\section{2) O papel (ou não) das idéias}

Quais foram as idéias que possibilitaram a "invenção" do Orçamento Participativo? O PT assumiu o poder em Porto Alegre com um programa que refletia as idéias dominantes no partido naquela época. Constituído por indivíduos oriundos de diversos movimentos sociais, o partido estava longe de ser uma organização dogmática ou homogênea quando assumiu o governo de Porto Alegre. Dois temas dominaram os debates sobre o que deveria ser feito. $\mathrm{O}$ primeiro se referia às obrigações dos governos do PT, que deveriam promover a participação popular em todos os níveis de poder. O segundo era que governos do PT deveriam "inverter as prioridades" em direção aos mais pobres.

Em 1989, com pouca experiência na gestão local, essas idéias eram ainda vagas. O Brasil encontrava-se na contramão da história, com o crescimento de um partido de ideologia socialista no momento em que os modelos socialistas internacionais existentes perdiam legitimidade rapidamente. Não havia ainda modelos claros do que depois veio a ser chamado do "Modo Petista de Governar" (Bittar, 1992). Assim, as propostas de participação e inversão de prioridades foram operacionalizadas de forma diversa em diferentes lugares. Podemos dizer que idéias participativas eram suficientemente aceitas tanto entre o partido no governo quanto entre importantes setores na sociedade civil para promover a criação de algum tipo de política participativa. Havia ainda a necessidade política de o PT se mostrar "competente embora diferente" na gestão local, favorecendo um certo espírito de experimentação. Mas não existiam modelos definidos que pudessem servir nem de "projeto institucional", nem de "cadeado cognitivo". Essa flexibilidade cognitiva facilitou a construção de uma política centrada na sinergia entre sociedade e Estado.

Depois desse momento de flexibilidade cognitiva, o próprio orçamento participativo, como formulado em Porto Alegre, tornouse um modelo amplamente imitado por várias razões. Por um lado, o governo daquela cidade conseguiu se reeleger múltiplas vezes. O OP foi associado, assim, a sucesso eleitoral. Dessa forma, a política de orçamento foi elogiada e estudada em diversas partes do mundo, desde 
entre intelectuais de esquerda até em organismos internacionais, como o Banco Mundial e as Nações Unidas. Quatro anos depois da sua implantação em Porto Alegre, o OP era política obrigatória em todos os municípios onde o PT se elegeu. Até o final da década, 140 municípios estavam desenvolvendo políticas parecidas ao OP. Desses, conforme estudo de Ribeiro \& Grazia (2003, p. 15), somente a metade eram governados pelo $\mathrm{PT}{ }^{12}$

Há vários sinais de que grande parte dessas experiências não produziu fóruns participativos caracterizados por disporem de autoridade. Das 103 experiências estudadas por Ribeiro \& Grazia (2003, p. 86), em somente 12 casos ocorre a deliberação sobre mais de $15 \%$ do orçamento! ${ }^{13}$ Embora isso não seja o único indicador de autoridade, é suficiente para levantar a desconfiança de que, como no caso dos comitês de bacia, grande parte dos orçamentos participativos são espaços apenas formais. A análise por Wampler do caso de Recife sugere que, de fato, a baixa alocação orçamentária é associada com a falta de autoridade:

De 1995 a 2000, apenas $10 \%$ dos gastos com investimento foram decididos no interior do OP. Como conseqüência, os participantes do OP buscavam também outros canais através dos quais eles poderiam conseguir influenciar o governo a implementar suas demandas. O nível baixo de alocação orçamentária enfraqueceu o OP como uma alternativa importante de tomada de decisão. (Wampler, 2002, p. 69)

$\mathrm{O}$ argumento desenvolvido explica a falta de autoridade descrita por Wampler em Recife pela falta de sinergia entre sociedade e Estado. Ao se tornar apenas um modelo a ser seguido, o OP passa a não representar mais uma "descoberta", em que atores das duas esferas se motivam para criar e apoiar um novo tipo de espaço decisório participativo. Por um lado, ao simplesmente imitar a experiência de Porto Alegre, o desenho da política pode se tornar incompatível com o imperativo de atrair participantes. Isso é mencionado por Silva (2002, p. 176), ao notar que na cidade de Viamão, região metropolitana de Porto Alegre, as taxas de participação eram muito mais baixas do que em outro lugares. Parte da explicação é que os formuladores da política não adaptaram o modelo de divisão da cidade em regiões orçamentárias às condições específicas do município, onde $80 \%$ da população ocupa apenas $20 \%$ do território. 
Por outro lado, existem muitas evidências de que a aplicação do modelo de OP não resulta em fóruns caracterizados por autoridade quando o governo não tem comprometimento político real em transferir poder decisório para o OP (Mendes, 1999; Wampler, 2002, p. 77). Nem sempre a implementação do OP sem comprometimento político reflete o que Souza chama de "oportunismo" (2002, p. 134-36). O caso de Viamão é de novo interessante porque, embora setores do governo petista fossem a favor do OP, divisões internas e "a identificação do OP como iniciativa de um grupo/setor do governo e não do seu conjunto" dificultaram a mobilização de apoio governamental em torno da política (Silva, 2002, p. 178). Ou seja, quando o modelo é reproduzido sem a adaptação adequada aos interesses locais, tende a não gerar autoridade. Pelo contrário, quando visto como imposição "de fora", pode sofrer boicotes que comprometem as chances de sucesso da política.

\section{Conclusões}

Em muitos sentidos, as experiências descritas acima não poderiam ser mais diferentes. O orçamento participativo é uma política local, que opera primordialmente com bairros, enquanto os comitês de bacia procuram lidar com o que são essencialmente questões regionais. Enquanto o OP começou trabalhando com apenas um tipo de organização da sociedade civil - as associações de moradores os comitês de bacia tentam envolver um largo espectro de grupos: ONGs, associações profissionais, acadêmicos, e, o que é mais contrastante, indústrias, agricultores e empresas públicas. É provável que a construção de sinergia Estado-sociedade seja sempre mais difícil nesses casos, pois as complexidades e multiplicidades de interesses dificultariam o encontro de pontos em comum. Mas, onde tal sinergia ocorreu, podemos identificar uma série de semelhanças entre os dois tipos de política.

\section{As estratégias políticas de atores estatais}

Em certas circunstâncias, os atores estatais acreditam que a criação de espaços participativos resultará em maior apoio político para o partido ou grupo que investe em sua promoção. Os casos 
apresentados sugerem que essa busca por apoio ocorre tanto quando os atores do Estado procuram contestar as relações de poder existentes, quanto quando meramente procuram garantir sua sobrevivência política. Em Porto Alegre, a política participativa teve um papel crucial na montagem de uma coalizão política alternativa, que pode, então, questionar o poder político tradicional da cidade. De forma parecida, atores políticos do Estado, tanto estaduais quanto municipais, freqüentemente apoiaram os comitês de bacia para terem acesso a recursos de instituições multilaterais ou de agências governamentais de nível mais alto.

\section{Problemas concretos}

A comparação de experiências participativas também sugere que a mobilização convergente de atores do Estado e da sociedade civil está relacionada à capacidade de resolver problemas concretos. Em Porto Alegre, atores do Estado aderiram ao OP não apenas porque a participação era uma iniciativa politicamente popular, mas também porque o foco inicial da política em pequenas obras comunitárias proporcionava objetivos realistas, possíveis de serem alcançados dentro das modestas possibilidades do governo municipal. Resolver esses problemas era de interesse tanto do governo quanto da sociedade, na medida em que, além de ajudar o governo a formar uma imagem de bom administrador, mobilizou moradores que priorizavam a falta de infra-estrutura básica como o problema mais grave para a sua vida cotidiana.

A identificação de problemas concretos com o potencial de mobilizar atores do Estado e da sociedade tem sido bem mais difícil na área de gestão de águas, mas, onde isso ocorreu, os comitês foram mais capazes de adquirir autoridade. A mobilização ocorreu não em função da existência ou dimensão dos problemas, que, em geral, eram antigos, mas pela súbita perspectiva de solução, que levou as pessoas a formarem alianças na busca de objetivos específicos: o controle de enchentes, um método de alocação de água, etc.

\section{Dando escala às motivações}

Se é mais fácil gerar motivação quando os fóruns participativos são vistos como mecanismos para a solução de problemas concretos, 
qual será a probabilidade de que as pessoas apóiem processos participativos em torno de questões menos concretas, ou quando os retornos aos participantes são menos imediatos? Problemas estão ligados a interesses. Algumas pessoas estão mais propensas a se mobilizarem pela solução de um problema específico do que outras. $\mathrm{Na}$ formulação de políticas participativas, portanto, a escolha dos problemas a serem enfrentados é crucial na determinação de quais grupos serão motivados a participar. Em Porto Alegre, a ênfase em pequenas obras mobilizou moradores pobres mas pouco efeito teve sobre a classe média. Os comitês de bacia têm mais dificuldade em mobilizar os pobres, exceto no caso do Ceará, onde pequenos produtores deram tanta prioridade ao problema de escassez quanto outros grupos. Nas regiões onde questões ambientais são o problema central de uma bacia, parece difícil atrair usuários e ainda mais difícil mobilizar os pobres, que raramente vêem tais problemas como sua prioridade central. Nesses casos, os participantes do lado da sociedade tendem a ser atores cuja vida não depende imediatamente da resolução de problemas relacionados à água, mas que vêm o tema, de forma clara, como prioridade política em função de convicções ideológicas: ambientalistas, pesquisadores e profissionais empenhados na melhoria das condições ambientais e na promoção da idéia de reforma na gestão de recursos hídricos.

Ambos os estudos de caso sugerem que uma forma de mobilizar participação em torno de questões menos imediatas é a construção de expectativas a partir de sucessos obtidos em questões concretas. No $\mathrm{OP}$, a eficácia das decisões participativas em torno de pequenas obras aumentou a credibilidade de tal processo de tomada de decisões, tanto aos olhos dos participantes quanto na visão dos atores de Estado, políticos e técnicos. Os participantes também mudaram a percepção dos problemas que enfrentavam, reconhecendo sua ligação com questões maiores e de mais longo prazo, ganhando portanto motivação para continuar participando (Abers, 1998, 2000). Nos casos dos comitês de bacia, processo semelhante parece ocorrer: a mobilização obtida para resolver problemas específicos dá ao comitê credibilidade para enfrentar questões menos imediatas. Mesmo nos casos dos comitês que se mobilizaram para ter acesso a recursos financeiros, como em São Paulo, os participantes ganharam experiência em processos de 
decisão participativa e, mais tarde, puderam enfrentar questões mais complexas e abstratas.

Duas ordens de motivos parecem explicar porque as pessoas expandem o seu horizonte de interesses após a mobilização bemsucedida em torno de questões concretas. Em primeiro lugar, a experiência na resolução de problemas ajuda as pessoas a perceberem quais são, de fato, os seus problemas, relacionando-os a causas mais complexas e menos imediatas. Em segundo lugar, o sucesso na solução de questões imediatas aumenta a sensação de "eficácia política", ou seja, lhes dá a confiança de que processos participativos podem ser recompensadores. A experiência de participação bem-sucedida empresta credibilidade ao próprio processo participativo tanto aos olhos dos atores de Estado quanto dos atores da sociedade. ${ }^{14}$

\section{Idéias e a importância da criatividade}

A maioria dos estudos que aplicam teorias de ação coletiva focalizam o indivíduo e seus interesses egoístas. Aqui, no entanto, sugiro que idéias, especialmente idéias técnicas, podem ter uma forte influência na percepção de tais interesses. Nos dois campos examinados aqui, podemos verificar a influência de idéias na reprodução de experiências participativas em ampla escala. No caso dos comitês, a aceitação, bastante difundida no meio técnico, de um modelo de gestão participativa, fortalecida por exigências políticas de organismos de financiamento, tem ajudado a legitimar a criação de espaços participativos. No caso dos orçamentos participativos, o modelo de Porto Alegre tem se difundido não somente por aceitação entre técnicos mas também pelo desejo de reproduzir o sucesso político do governo daquela cidade. ${ }^{15}$

A popularidade de idéias participativas torna mais provável a inclusão de mecanismos participativos nas políticas públicas de orçamento municipal ou de gestão de bacia. Mas nem sempre essas idéias são relevantes ao contexto específico em que os atores agem. Em ambos os casos discutidos aqui, é possível verificar que modelos, ao mesmo tempo em que abrem o campo da formulação de políticas públicas para alternativas participativas, podem dificultar a construção de políticas específicas que refletem interesses compartilhados. Essa 
dificuldade parece ocorrer quando, em vez de adaptar modelos a circunstâncias específicas, os atores optam por implementá-los cegamente, mesmo que os problemas previstos no modelo original não pareçam relevantes ou que as fórmulas de resolução não pareçam efetivas. Em alguns casos, é preciso adaptar modelos a circunstâncias específicas. Em outros, os modelos existentes são totalmente inadequados para as circunstâncias. Portanto, uma questão importante para pesquisas futuras é investigar os condicionantes da criatividade: por que e como alguns grupos de atores, em alguns casos, se libertam dos modelos existentes, flexibilizando-os ou até abandonando-os na busca de sinergia? ${ }^{16}$

\section{Notas}

1 Veja Cook \& Kothari (2001) para uma crítica à disseminação massiva da idéia de participação.

2 Em nome da simplicidade, este artigo focaliza o papel das idéias nas decisões dos atores estatais que formulam políticas participativas. Devese notar, no entanto, que a influência de idéias não se limita apenas aos atores estatais ou aos formuladores das políticas: os cidadãos chamados a participar também podem ser influenciados por idéias tanto positiva quanto negativamente. Por exemplo, pode-se imaginar uma situação em que atores da sociedade são influenciados pela idéia, até recentemente predominante entre movimentos sociais de esquerda, de que o Estado nunca compartilharia poder decisório na prática. Tal concepção poderia levar ao não reconhecimento de uma oportunidade de realmente influenciar decisões governamentais.

3 O Projeto Marca d’Água é um estudo colaborativo que reúne pesquisadores brasileiros e estrangeiros, além de profissionais envolvidos na criação de comitês. Em 2001, o projeto realizou 23 estudos preliminares sobre bacias hidrográficas, das quais 18 tinham comitês. Relatórios apresentando os resultados estão disponíveis no sítio do Projeto, (http:// www.marcadagua.org.br) e foram resumidos por Formiga \& Lopes (2003). Dois dos casos são fruto de minha própria pesquisa, envolvendo entrevistas com cerca de 15 informantes-chave em cada bacia, análise de documentos e atas de reuniões. Além dessas pesquisas em bacias hidrográficas, tenho realizado entrevistas com atores envolvidos na reforma do sistema federal de gestão de recursos hídricos e no Estado de Minas Gerais. Essas entrevistas também informaram as reflexões aqui apresentadas. 
4 Além do Paraíba do Sul, o único exemplo de cobrança ocorre no Ceará, mas sem a efetiva participação dos comitês no processo.

5 Margaret Keck, comunicação pessoal.

6 Essa tendência está sendo revelada na análise da base de dados que o Projeto Marca d'Água está sistematizando, a partir da codificação de atas de comitê. Na maioria dos comitês incorporados até agora, os assuntos discutidos são relacionados à organização interna. Veja Rocha (2003) e Nogueira (2003).

7 A exceção é a bacia do Paraíba do Sul, considerada como caso piloto para cobrança pela Agência Nacional de Águas. Após investimento intenso em cadastramento e outras preparações, os primeiros boletos de cobrança foram emitidos em março de 2003.

8 Agradeço esta percepção a Maria Carmen Lemos.

9 Deve-se notar que alguns estudos mais recentes sugerem que, depois de 15 anos de implementação, o OP de Porto Alegre vem mostrando sinais de "esgotamento" como espaço de democratização das decisões públicas. Veja principalmente Navarro (2002), que argumenta que a partir dos meados da década de 90, o OP começou a refletir um "novo clientelismo", com o aumento do controle partidário (pelo PT) das decisões.

10 Pesquisas de opinião realizadas durante as primeiras duas administrações mostraram que essa popularidade era, em primeiro lugar, resultado de uma imagem de competência. Em segundo lugar, vinham as percepções de justiça social e de combate à corrupção.

11 Esta conclusão contradiz a visão comum de que processos participativos, por serem demorados e dirigidos por opiniões sem base técnica, tendem a dificultar a administração efetiva. Veja Abers (2000, p. 88-89).

12 Veja Avritzer e Navarro (2002), para um conjunto de estudos de experiências de OP.

13 As autoras notam a grande dificuldade em obter respostas para esta pergunta. Não foi possível informar a porcentagem deliberada em 38 dos 103 casos. No entanto, a diferença entre os casos com maior poder deliberativo e os com menor é claro: em 10 casos não se delibera sobre recursos, e em 43 casos delibera-se sobre entre 0 a $15 \%$ do orçamento.

14 Veja Pateman (1992) para uma discussão teórica do poder "educativo" da participação e da idéia de que experiências em torno de assuntos pequenos podem servir como gatilho para participação em torno de assuntos mais amplos. 
15 Deve-se notar que a disseminação de modelos não resulta apenas da influência de idéias. Di Maggio e Powell (1991) argumentam que há três forças que promovem a disseminação de modelos organizacionais: coerção, processos miméticos e pressões normativas. Essa última trata da disseminação, especialmente entre profissionais, de idéias. Mas podemos também identificar as outras duas forças nos exemplos tratados aqui: a coerção é refletida nas políticas federais e de bancos internacionais, que exigem a inclusão de mecanismos participativos para que se obtenha financiamento. $\mathrm{O}$ mimetismo aparece quando outras prefeituras procuram reproduzir o sucesso político de Porto Alegre.

16 Abers e Keck (2003) propõem um marco analítico para estudar estes processos no contexto de comitês de bacia.

Abstract: This article analyzes participatory policies created by the State from the perspective of "authority", the capacity of these new decision-making forums to solve problems, enforce decisions and have an impact on the external world. Based on examples from two types of participatory policy - river basin committees and participatory budgets - it argues that the construction of authority is more likely to occur when both State and society actors perceive the new decisionmaking process as beneficial to their interests. On the one hand, the article shows how, in successful cases, actors design participatory policy around shared interests. On the other hand, it examines how cognitive factors can both facilitate and make more difficult the identification of such interests. The article argues that technical ideas, such as participatory models, can help actors to perceive the creation of participatory forums as in their interest. However, when models are followed blindly, they can become "cognitive locks", making it more difficult for actors to adapt the ideas to local conditions.

Key-words: participatory policy, river basin committees, participatory budgeting, collective action, ideas.

Resumé: Cet article analise les politiques participatives, créées par l'État, dans la perspective de «l'autorité », c'est-à-dire la capacité des nouveaux foruns de prise des décisions de trouver des solutions pour les problèmes, de faire valoir les décisions prises et d'avoir de l'impact dans le monde extérieur. À partir de l'exemple de deux types des politiques participatives - les comités de bassin hydrographique et les "budgets participatifs" (orçamentos participativos) -, il est montré que la construction de l'autorité est plus probable dans les cas où tant 
les acteurs de l'Etat que les acteurs de la société perçoivent que le nouveau processus de prise de décision peut béneficier leurs intérêts. L'article montre, d'une part, comment les acteurs impliqués dans les expériences réussies formulent les politiques participatives autor des intérêts partagés. D'autre part, il est éxaminé les facteurs cognitifs que facilitent ou, au contraire, rendrent plus difficile l'identification de tels intérêts. Il est encore montré que les idées techniques, telles que les modèles de participation, peuvent aider les acteurs à percevoir la création des espaces participatifs comme de leurs propres intérêts; toutefois, lorsque ces modèles sont suivis aveuglement, ils peuvent devenir des "cadenas cognitifs", en rendrant difficile la capacité d'adaptation des idées aux conditions locales.

Mots-clés: politiques participatives, comités de bassin hydrographique, budget participatif, action collective, idées.

\section{Referências bibliográfics}

ABERS, Rebecca. do clientelismo à cooperação: políticas participativas e organização da sociedade civíl em Porto Alegre. Cadernos IPPUR, v. 12, n. 1, p. 47-78, jan./jul. 1998.

. Inventing local democracy: grassroots politics in Brazil. Boulder: Lynne Rienner, 2000.

. Practicing radical democracy: lessons from Brazil. DISP, v. 147, n. 4, 2001.

. A Bacia do Rio Paranoá, Distrito Federal: relatório de pesquisa, Projeto Marca d’Água. 2002a. Disponível em: <http:// www.marcadagua.org.br>.

A Bacia do Rio das Velhas, Minas Gerais: relatório de pesquisa, Projeto Marca d'Água. 2002b. Disponível em: <http:// www.marcadagua.org.br>.

ABERS, Rebecca; KECK, Margaret. Networks, relations and practices: reflections on watershed management organization in Brazil. Trabalho apresentado no XXIV International Congress da Latin American Studies Association (LASA), Dallas, 27-29 de março de 2003.

AVRITZER, Leonardo; NAVARRO, Zander (Orgs.). A inovação democrática no Brasil: o orçamento participativo. São Paulo, Cortez, 2002. 
BITTAR, Jorge. O modo petista de governar. São Paulo: Teoria e Debate, 1992.

BRAANSTROM, Christian. A Bacia do Sorocaba-Médio Tietê, São Paulo, relatório de pesquisa, Projeto Marca d'Agua, 2002. Disponível em: <www.marcadagua.org.br>.

BRANCO, Mônica de Andrade Gonçalves. O financiamento da gestão participativa da água: o caso do FEHIDRO. 2002. Dissertação (Mestrado) - Centro de Desenvolvimento Sustentável, Universidade de Brasília,

BLYTHE, Mark. The transformation of the Swedish model: economic ideas, distributional conflict and institutional change. World Politics, p. 126, 2001.

CIDADE. Quem é o público do Orçamento Participativo: seu perfil, porque participa e o que pensa do processo. Porto Alegre: CIDADE, 1999.

COOKE, Bill; KOTHARI, Uma (Orgs.). Participation: the new tyranny? London: Zed, 2001.

DI MAGGIO, Paul J.; POWELL, Walter W. The iron cage revisited: institutional isomorphism and collective rationality in organizational fields. In: POWELL, Walter W.; DI MAGGIO, Paul J. (Orgs.). The new institutionalism in organizational analysis. Chicago, University of Chicago Press, 1991. p. 41-62.

EVANS, Peter. Government action, social capital and development: reviewing the evidence on synergy. World Development, v. 24, n. 6, p. 10331103, 1996.

FEDOZZI, Luciano; POZZOBON, Maria Regina; ABERS, Rebecca. Orçamento participativo: pesquisa sobre a população que participou da segunda rodada de assembléias do orçamento participativo da prefeitura municipal de Porto Alegre. Porto Alegre, CIDADE, FASE. 1995. Fotocópia.

FORMIGA JOHNSSON, Rosa Maria. Les eaux brésiliennes: analyse du passage à une gestion intégrée dans l'Etat de São Paulo. 1998. Dissertação (Doutorado) - Université Paris XII - Val de Marne, Specialité: Sciences et Techniques de l'Environnment,

FORMIGA JOHNSSON, Rosa Maria; LOPES, Paula. (Orgs.). Projeto Marca d’Água, caderno 1: retratos $3 \times 4$ das bacias estudadas. Brasília: FINATEC, [no prelo].

GARJULI, Rosana; OLIVEIRA, João Lucio Farias de; CUNHA, Marcos André Lima da; SOUZA, Edcarlos Rulim de. A Bacia do Rio 
Jaguaribe, Ceará: relatório de pesquisa, Projeto Marca d'Água. 2002. Disponível em: <www.marcadagua.org.br>.

GUTIERREZ, Ricardo. A Bacia do Rio Gravataí, Rio Grande do Sul: relatório de pesquisa, Projeto Marca d'Agua. Versão Preliminar, 2001.

FRANK, Beate; BOHN, Noemia. Gestão de bacias: um caminho de mão dupla: reflexões sobre a experiência do Comitê do Itajaí. 2000. Disponível em: <http://www.oieau.fr/riob/ag2000/artigo_RIOB.htm>.

KECK, Margaret E. Water, water, everywhere, nor any drop to drink: land use and water policy in São Paulo, Brazil. In: EVANS, Peter. (Org.). Livable cities? urban struggles for livelihood and sustainability. Berkeley: University of California Press, 2002a. p. 162-94.

KECK, Margaret E. A bacia do litoral norte, São Paulo: relatório de pesquisa, Projeto Marca d'Agua. 2002b. Disponível em: <www.marcadagua.org.br〉.

KEMPER, K.; OLSON, D. Water pricing: the dynamics of institutional change in Mexico and Ceará, Brazil. In: DINAR, Ariel (Ed.). The political economy of water pricing reforms. Boulder, CO: Netlibrary, 2001.

LEMOS, Maria Carmen; OLIVEIRA, João Lúcio Farias de. Water reform across the state/society divide: the case of Ceará, Brazil. 2003. Fotocópia,

MAIS, Ivanir. A Bacia do Itajaí, Santa Catarina: relatório de pesquisa, Projeto Marca d'Água. 2002. Disponível em: 〈www.marcadagua.org.br〉.

MARCH, James G.; OLSEN, Johan P. Rediscovering institutions: the organizational basis of politics. New York: The Free Press, 1989.

MARQUETTI, Adalmir. Democracia, eqüidade e eficiência: o caso do orçamento participativo em Porto Alegre. Trabalho apresentado no seminário: Orçamento Participativo: a experiência sob o olhar do mundo, Porto Alegre, 31 de maio a 2 de junho de 2001.

MELLUCCI, Alberto. Nomads of the present: social movements and individual needs in contemporary society. London, Hutchinson Radius, 1989.

MENDES, Denise Maria Lima. Entraves internos à implementação do orçamento participativo do Distrito Federal. 1999. Monografia (Especialização em Políticas Públicas) - Departamento de Ciência Política, Universidade de Brasília.

NAVARRO, Zander. O Orçamento Participativo de Porto Alegre (1989-2002): um conciso comentário crítico. In: AVRITZER, Leonardo; NAVARRO, 
Zander (Orgs.). A inovação democrática no Brasil: o orçamento participativo. São Paulo: Cortez, 2002. p. 89-128.

OLSON, Mancur. The logic of collective action. Cambridge, MA: Harvard University Press, 1965.

PATEMAN, Carole. Participação e teoria democrática. São Paulo: Paz e Terra, 1992.

RIBEIRO, Ana Clara Torres; GRAZIA, Grazia de. Experiências de Orçamento Participativo no Brasil: período de 1997 a 2000. Petrópolis, RJ: Ed. Vozes, 2003.

SABATIER, Paul. An advocacy coalition framework of policy change and the role of policy-oriented learning therein. In: McCOOL, Daniel C. (Ed.). Public policy theories, models and concepts: an anthology. Englewood Cliffs, NJ: Prentice Hall, 1995.

SELZNICK, Phillip. TVA and the grassroots. Berkeley: University of California Press, 1949.

SILVA, Marcelo Kunrath. A expansão do orçamento participativo na região metropolitana de Porto Alegre: condicionantes e resultados. In: AVRITZER, Leonardo; NAVARRO, Zander. (Orgs.) A inovação democrática no Brasil: o orçamento participativo. São Paulo: Cortez, 2002. p. 157-188.

SOUZA, Marcelo Lopes de. Para que serve o orçamento participativo? Disparidade de expectativas e disputa ideológica em torno de uma proposta em ascensão. Cadernos IPPUR, v. 14, n.2, p. 123-142, 2002.

TARROW, Sidney. Power in movement: social movements, collective action and politics. Cambridge: Cambridge University Press, 1994.

TILLY, Charles. From mobilization to revolution. Reading, MA: AddisonWesley, 1978.

WAMPLER, Brian. Orçamento Participativo: uma explicação para as amplas variações nos resultados. In: AVRITZER, Leonardo; NAVARRO, Zander. (Orgs.). A inovação democrática no Brasil: o orçamento participativo. São Paulo: Cortez, 2002. p. 61-88.

WEIR, Margaret. Ideas and the politics of bounded innovation. In: STEINMO, Sven; THELEN, Kathleen; LONGSTRETH, Frank (Orgs.). Structuring politics: historical institutionalism in comparative analysis. Cambridge: Cambridge University Press, 1994.

WEYLAND, Kurt. Limitations of rational choice institutionalism for the study of Latin American politics. Comparative International Development, v. 37, n.1, p. 57-85, 2002. 